The Geneva Papers on Risk and Insurance, 20 (No. 75, April 1995) 187-196

\title{
Underwriting Motor Profitability - The Malaysian Approach -
}

\author{
by Lim Chia Fook*
}

\section{Introduction}

The Malaysian insurance industry has undergone many changes over the past decade. These changes have brought about positive and profound improvements to the operation of general insurance companies. Some of these changes arose from insurers' desire to selfregulate whilst some measures arose out of substantial progress in insurance legislation.

For motor insurance, these milestones in the industry include the introduction of CashBefore-Cover regulations (1980), the Approved Repairers Scheme (1982), the Inter-Company Agreement on Motor (1986) and the Inter-Company Agreement on Agencies (1987).

There is no doubt that motor insurance in Malaysia continues to be a class of business requiring special attention. In order to fully appreciate the approach adopted by the Malaysian industry to improve motor business, we need to examine first of all the problems of the Malaysian market which is not unique to us.

The general insurance industry's total written premium in 1992 amounted to RM 2.9 billion. The 1993 estimated figure is RM 3.2 billion. These constitute annual growth rates of $20.6 \%$ and $11.1 \%$ respectively.

The total written premium contribution from motor business was about $43 \%$ or RM 1.7 billion in 1993. For the corresponding period, fire business contributed $22 \%$ of total written premium and the marine aviation and transit sector contributed about $10 \%$. The other miscellaneous accident/liability business accounted for the remaining $25 \%$ of written premiums.

The claims experience of motor insurance in Malaysia for 1985 to 1993 is illustrated in the table below:

\footnotetext{
* General Manager, General Insurance Association of Malaysia, Kuala Lumpur.
} 
Motor Insurance Claims

\begin{tabular}{|c|c|c|c|c|c|c|}
\hline \multicolumn{4}{|c|}{ Written premium in millions $(\mathrm{RM})^{*}$} & \multicolumn{3}{c|}{ Incurred claims ratio in percent } \\
\hline YEAR & ACT & OTHERS & TOTAL & ACT & OTHERS & TOTAL \\
\hline 1985 & 106 & 320 & 427 & 104.8 & 65.2 & 75.1 \\
\hline 1986 & 116 & 311 & 427 & 112.4 & 66.8 & 78.9 \\
\hline 1987 & 116 & 306 & 422 & 109.6 & 66.7 & 78.5 \\
\hline 1988 & 116 & 355 & 471 & 173.2 & 67.8 & 94.9 \\
\hline 1989 & 152 & 490 & 643 & 144.0 & 67.0 & 85.9 \\
\hline 1990 & 182 & 629 & 812 & 198.6 & 58.9 & 91.1 \\
\hline 1991 & 203 & 817 & 1,021 & 321.9 & 68.5 & 120.6 \\
\hline 1992 & 225 & 1,084 & 1,309 & 141.1 & 55.5 & 70.6 \\
\hline 1993 & 244 & 1,121 & 1,365 & 155.3 & 47.4 & 65.9 \\
\hline
\end{tabular}

* US\$ $1.00=$ RM 2.60 (approximately).

I need to explain the use of the terms "Act" and "Others" in motor insurance in the Malaysian context. The Road Transport Act, 1987 and its predecessor, the RoadTraffic Ordinance, 1958 require motor vehicle owners in the country to obtain motor insurance against liability for third party bodily injury and death as a pre-requisite to motoring on Malaysian roads. This compulsory insurance cover constitutes the "Act" cover. The "Others" portion would cover the insured's own damage and third party property damage.

The overall incurred claims ratio i.e. for "Act" and "Others" combined has been steadily increasing from $75 \%$ in 1985 to almost $120 \%$ in 1991 . In the subsequent two years, however, results improved dramatically to $70.6 \%$ and $65.9 \%$ in 1992 and 1993 respectively. The incurred claims ratio for the "Others" portion of business has remained fairly steady and may even be considered "profitable". It is not, however, the practice to insure "Act" liability as a separate class of insurance.

It is very pertinent, in analyzing the incurred claims ratios, to bear in mind the impact of additional provisions made by a few insurers especially in 1991 to "replenish" reserves for claims intimated as well as incurred but not reported (IBNR) claims at the request of the regulators.

The Malaysian general insurance industry prior to 1985 was confronted with a multitude of problems, many of which related directly to motor insurance:

- Corporate philosophies and strategies that emphasized premium growth rather than profitability i.e. cash-flow underwriting. This was a cause and effect of the dominance of market and sales oriented personnel in the higher levels of the companies' hierarchy and the lack of insurance fundamentals amongst shareholders and directors.

- Lack of control particularly in respect of underwriting - acceptance of risks, issuance of cover-notes/policies and payment of claims. 
- High management expenses tending to increase over the years.

- High acquisition costs through payment of excessive commission to intermediaries.

- High claims processing costs - workshops and repairers kept increasing their charges. There was no agreed schedule of fees for doctors and lawyers. Legal and medical charges as well as court awards have increased over the years.

- Unprofessional rating and rate-cutting due to competition. A centralized database for various classes of business was absent.

- Outstanding premiums and failure to actively collect premiums.

- Unprofessional intermediaries and lack of regulation of these intermediaries by insurers.

- Fraud - especially in motor insurance.

The strategy that was adopted to overcome these problems involved a multipronged approach in the following areas:

a) Acquisition Costs Control.

b) Professionalizing and Regulating the Intermediary.

c) Combating Fraud and Control of Workshops.

d) Instituting Underwriting and Operational Controls by Insurers.

\section{Acquisition cost control}

Motor insurance business in Malaysia is conducted through the use of a Motor Tariff. The tariff embodies the general regulations, policy and extension wordings as well as the rating schedules for private cars, commercial vehicles, motor-cycles and the motor trade. One of the tariff's objective is to create a level playing field on which underwriters will conduct motor business. Hence, the tariff also provided for Agency Rules which governed the commissions payable to intermediaries.

Regrettably, in the 70 s and early $80 \mathrm{~s}$, breaching the agency rules became widespread especially with impetus from the twin pressures of competition for market share and cashflow underwriting. In order to recruit and attract more agents and business, insurers paid excessively high commissions to the agents and many imaginative methods were employed to circumvent the agency rules.

This led to the introduction of an Inter-Company Agreement on Motor (ICAM) on 1st March, 1986 by the industry following the footsteps of the successful implementation of an Inter-Company Agreement on Fire (ICAF) in the previous year. As with the ICAF, the ICAM was an agreement signed by all general insurers which sought to enforce all aspects of the provisions of the motor tariff. What was most significant was that these agreements placed restrictions on the maximum commissions payable to intermediaries and provided for inspections and penalties for non-compliance.

The efforts of the industry to regulate its acquisition costs to a more reasonable level was later endorsed and supported by the Malaysian Insurance Regulatory Authorities which introduced maximum limits on commissions for all classes of general insurance business with effect from 1st January, 1991. The guidelines also addressed the management expenses ratio of insurers by limiting the management expenses limit for direct general insurance 
business to $20 \%$ of gross direct premium for the interim period 1991 to 1993 . From 1994, management expenses on direct general insurance business were further limited to $15 \%$ of gross direct premiums.

\section{Jrofessionalizing and regulating the intermediary system}

The general insurance industry through its trade association (the General Insurance Association of Malaysia) has since March 1985 sought to mitigate the extent of problems created by a multi-layered insurance intermediary system in the country.

Prior to this period it was normal to find operating alongside the legitimate/licensed elements of insurance company branches, brokers and agents, various components such as insurance consultants and sub-agencies. In the latter there may be several layers of subagencies to contend with.

This parallel system operated on the fringes of the market and was out of reach of the regulatory authorities. However, it was as equally active as its supervised counterparts.

The proliferation of "sub-agencies" arose mainly because agents appointed by insurers could and did appoint their own agents resulting in a multi-tiered agency system. It was not uncommon for each link in this multi-tiered system to unaware of all else except those immediately before or after in the chain. An unconditional exercise to register agents in $1985 / 86$ revealed a total of about 16,500 agents. These agents represented from one to in some cases as many as eight insurers at any one time.

Prior to 1988, there was no requirement to confine an agent to a particular principal or to a limited number of principals. Consequently, the same agent could act for a number of competing principals even in the same class of business and pitch one against the other. The lack of identification of insured with particular insurers meant that agents could shift a particular insured from insurer to insurer with the choice of insurer based mainly on the amount of commissions and terms that the insurer was willing to extend to the agent.

Insurers keen to obtain a larger share of the market to a large extent ignored agreed tariffs and agreed remuneration limits for intermediaries. The commission costs of insurers in the early 1980 s were excessive and were as high as $45 \%$ in motor insurance and as high as $60 \%$ in other classes of general insurance as a consequence of this competition for business.

In 1988, the industry through the trade association sought to register all general insurance agents as a means to regulate and monitor the development of the insurancc agency network in Malaysia. The insurance industry implemented the Inter-Company Agreement on Agencies (ICAA) on 1st January, 1988.

In principle, the ICAA was an agreement between general insurers to transact business only with agents registered as such with the General Insurance Association of Malaysia. The parties to the agreement acknowledged the need to rationalize their own practices vis $a$ vis the existing agency system.

The salient features of the ICAA were as follows:

a) The registration of insurance agents and insurers would only transact business with registered agents.

b) Registered agents were permitted to conduct business for a maximum of two principals at any one time and must be registered accordingly. 
c) Multiple interests by substantive owners or directors or employees of a registered agency in any other insurance agency was not permitted. The second agency application would be refused registration.

d) Registered agents were not allowed to appoint any "sub-agents".

e) Registered agents were required to comply with maximum credit periods of 60 days in general. Where cash-before-cover business was concerned the agent must remit any premiums collected to the principal within 7 days in accordance with cash-before-cover regulations.

f) One of the criteria for registration was that the agent, or in the case of a firm or corporation, the corporate nominee, must fulfill an attendance course or an examination specifically designed for agents as indication of general proficiency in general insurance. Since 1st January, 1991, the attendance course was discontinued and intending agents must qualify in the examination course as a pre-requisite for registration.

As with other ICAs, the ICAA also provides for inspections of companies to ensure compliance and penalties for any breaches.

To large extent the adverse image of the general public towards the insurance industry has been a result of the activities of insurance agents who are in the front-line. Public complaints include lack of professional advice, high pressure sales methods, transmission of policy documents, absconding with premiums and lack of after-sales service. These complaints are more acute in motor as roughly more than $80 \%$ of all complaints to the insurance regulatory authorities relate to motor insurance.

The positive ramifications of the ICAA and the registration of agents have been felt in all classes of business but have had the greatest impact on the motor sector because of the importance of agents in the motor insurance distribution network.

The ICAA provides for disciplinary action to be taken against agents who do not operate within the confines of an accepted code of ethics for intermediaries. Errant agents can be warned of having their registration suspended or terminated if they are found guilty of misconduct. Agents found guilty of serious offenses such as fraud and criminal breach of trust against policyholders or insurers would not be allowed to be re-registered. This mechanism is extremely useful in inculcating some measure of discipline in the agency force.

Secondly, the registration of agents has provided useful information for training of the industry's agency force. A limited start has been made in exposing general insurance agents to formal insurance education by way of the mandatory pre-registration examinations to test for general proficiency which was specially designed for agents by the Malaysian Insurance Institute.

There is no doubt that providing appropriate educational opportunities to insurance agents is the only way to improve their professionalism. With specially designed training modules starting with motor insurance, it is possible to bring these previously experiencetrained agents into the mainstream of formally educated insurance professionals. The same methods have been applied to life insurance agents and have proven successful.

Thirdly, the restriction of an agent to a maximum of two principals at any one time has limited the agents' inclination towards playing off one insurer against another to get the best terms. Agents have also to reconsider their business portfolio as they now are not in a position to lay-off unattractive business to other insurers. 
Fourth, the introduction of a letter of release by principals to agents who are terminated or wish to change principals allows the current principal to exercise control over outstanding premiums due from that particular agent. The principal can withhold the letter of release if there are outstanding matters between him and the agent. In order to inject a measure of equity in this arrangement, the Agency Board monitors any complaints of any unreasonaole actions by insurers.

\section{Premium warranty}

In conjunction with the provision under the ICAA which permitted agents to offer a maximum credit period of 60 days, the industry implemented a premium warranty for all classes of business other than insurances involving Cash-before-cover, Marine Cargo and Hull, bonds, CAR and EAR.

The premium warranty reinforces, upon the policyholder, the 60-day credit period that has been allowed to agents and was initially introduced to assist the agent in collection within this period.

The premium warranty provides that the policy will be voidable by the insurer in the event the premium due is not paid or received by the insurer within 60 days from the date of inception. For this purpose, receipt by an authorized agent of the insurer is deemed to be receipt by the insurer.

In the event the premium warranty is invoked, the insurer will be entitled to the pro rata premium for the period in which he was on risk. The premium warranty, however, makes it very clear that receipt of premium by insurance brokers is not deemed to be receipt by the insurer. In order to accommodate the practical limitations of transmission of fund from brokers to insurers, a special arrangement was agreed which allowed brokers to remit premiums collected to insurers within 15 calendar days from the date of receipt of the premiums by the broker. Insurance agents have also been granted the same period for remittance of premiums to their respective principals once the premiums have been collected.

Although the premium warranty does not directly affect motor insurance, the discipline it has brought to the market in terms of premium collection cannot be discounted. The premium warranty was introduced in 1988 and it is now well-known by agents, brokers and insured alike that the norm for payment of insurance premiums (other than motor) to insurers is 60 days.

\section{Combating motor fraud}

Fraud in underwriting, collection or premiums and settlement of claims can cause a serious strain on the results of motor insurance business through suppression of premiums and inflation of claims. Preventive measures need to be put in place to deter fraud. The industry must act collectively and expeditiously to tighten control over staff, intermediaries, adjusters and repairers, so tliat malpractice can be significantly reduced. As the effects of fraud not only make the business unprofitable for the insurer but also impact on the premiums which have to be paid by the honest policy-holders, it is vital that positive steps be taken to minimize fraud in the system.

Insurance fraud is as broad and complex as insurance itself. Insurance fraud is apparently an object of criminal exploitation the world over and unlike bad debts or conventional property crimes such as burglary are unfortunately not self-disclosing. Therefore any attempt at determination of the extent of insurance fraud in Malaysia would be purely speculative. 
Munich $\operatorname{Re}$ estimates that world-wide insurance fraud varies from $10 \%$ to $30 \%$ of the gross premium in the industrialized parts of the world. Even more disturbing and again to quote Munich Re, "Depending on the country and class of insurance in which the figures apply, it is estimated that claims payments resulting from fraud may account for as much as $50 \%$ of premium income".

Property damage fraud on motor vehicles places a strain on the results of motor underwriters. Efforts at implementing anti-fraud measures by the insurance industry have been a major pre-occupation of insurers and regulators alike.

Some of the major problems associated with repairs to accident damaged vehicles have been:

i) Good or undamaged parts are replaced with damaged parts to project a greater extent of damage as a result of the accident.

ii) Even if this is detected by insurers, it is difficult for owners of the vehicles or their insurers to remove the vehicles to alternative workshops as the existing workshop would impose cxorbitant towing charges and storage fees.

iii) Vehicles are towed to a workshop, usually either with the unwitting or forced agreement of the owners who are usually in a state of distress or submission. Insurers are prevented from using a workshop of their choice for this reason.

iv) A particular accident may become the subject of several insurance claims with differents insurers. The absence of a central reference point for all claims hampers detection of this.

v) In some instances the damage is exaggerated with the collusion of the owners who are promised improvements to their vehicles and/or that they will not be put out of pocket for the excess and will receive attention for unrepaired damage caused in prior accidents.

vi) (It has been suggested) there are instances of collusion between workshops, adjusters, claims officials, owners and personnel in authority to either exaggerate claims or fabricate losses/claims.

In order to combat these malpractices which had assumed serious proportions particularly in the major urban centers in the early 80s, the Malaysian Insurance Trade Association introduced the Approved Repairs Scheme in March, 1983. Repairers apply to be included in the Scheme. Members of the Association, through a secret balloting system, will nominate or veto workshops to be included in the Scheme annually. There are presently about 270 approved repairers. Insurers have the option to use only repairers listed in the Scheme or to select and add to the list. The insurer is, however, required to make known to their policyholders at the time of issue of cover that they are only permitted to send their vehicles to these panel of workshops for repairs in the event of accidents, failing which, the insurer will not be eligible for indemnity of the repair costs. This condition makes it attractive to repairers to remain in the Scheme or seek entry to it.

The Scheme has succeeded in that it provides insurers with an effective control mechanism as repairers can be blacklisted if they are found to be involved in fraudulent practices. The conduct of business between repairers and insurers has also improved as the repairers refrain from attempts at threats and intimidation of insurance claims personnel. The Scheme in vetting applications also ensures that approved repairers possess reasonable minimum facilities and are properly set-up to operate efficiently as repairers. 
The Scheme has also been successful in imposing a requirement on its approved repairers to tow vehicles at standard rates whether these are subject to repairs paid by insurers or are towed after mechanical breakdown. A standard tow contract was designed and widely circulated for use by the motoring public. The contract does not permit the tow company to dismantle and commerce repairs to the vehicle until permission is granted by the owner or the insurer. The tow contract would eventually set the standard for public expectations in terms of rates and services provided by tow-truck operators throughout the country.

In combating fraud, the exchange and pooling of information between insurers is an essential factor to uncover fraud which may otherwise go undetected. The members of the insurance association support three motor data bases. Firstly, all stolen vehicles are reported to the association. These are then compiled with their registration numbers; the engine and chassis numbers and other details of the vehicles and circulated to members. The list is also circulated to the Police, the RoadTransport Department and to the Association of Hire Purchase and Finance Companies.

Secondly, a list of total loss vehicles (whether actual or constructive) is maintained and similarly circulated. In addition, insurers return to the Road Transport Department the registration documents of vehicles which are total losses to prevent these documents from being recycled for stolen vehicles.

Thirdly, all claims paid above RM 5,000 are put into a data base that indicates losses paid for the same vehicle where the vehicle registers more than one paid claim. This, though a delayed mechanism, may nevertheless establish fraud the moment it is identified and provides evidence that claims monies may have been paid to fraudsters enabling further investigation by the police. At the same time, the system serves as a log on each vehicle's paid claim history.

The insurance association has expanded its efforts by establishing a computerized Management Information System for the industry. This MIS will initially consolidate comprehensive underwriting and claims data on motor and fire insurance primarily for the purpose of long term reviews of the tariffs but also equally important would be the analyses of these data to minimize opportunities for fraud and to uncover fraud against insurers.

No one appreciates the true cost of fraud more than insurers. Companies combat fraud diligently through their claims departments and special investigations with adjusters. However, the broad scope of the problem and the sophistication of "professional" insurance criminals cannot be overcome by the individual policyholder and separate efforts of insurance companies. A truly effective fight against fraud requires a united effort from insurers and public law enforcement agencies.

\section{Instituting underwriting and operational control}

If prevention is to be the key to deterrence of fraud against insurers, then it is vital to initiate these measures at the point of underwriting. The skills and experience of the motor underwriter, therefore, become critical. This is of course also true for all other classes of business.

Great efforts have been expended and will continue to be expended in the training of insurance staff and intermediaries in advancing their insurance underwriting skills. The emphasis on insurance knowledge per se is important but there is also a growing shift towards developing practical skills. Claims staff, for example, need to be trained to ensure that they are competent and well-qualified to spot potential fraud. 
Since 1990, insurers are required to expend a specified minimum standard for training expenditure. From 1994, this expenditure was increased to $4.5 \%$ of the preceding year's gross salary for each insurer. Those insurers who do not do so are required to pay a levy towards the training fund of the Malaysian Insurance Institute for the training of insurance industry personnel in general.

The dependence on agents for the procurement of motor business also exposes the industry to fraud by these agents. This has required insurers to exercise greater control over their agents particularly when it comes to motor business.

\section{Motor insurance liability claims}

The statistics presented earlier show that the losses are coming from the "Act" side i.e. liabilities for bodily injury and death. How then does one address the losses from the "Act" portion of motor insurance?

The present system of motor accident compensation in Malaysia may be summarized as follows:

- The law governing indemnity in instances of personal injury and death as a result of motor accidents is governed by the Civil Law Act, 1956 as amended by the Civil Law (Amendment) Act, 1984. The law provides a large degree of discretion to the judiciary in determining the quantum of awards.

- In addition, as in other countries influenced by English common law, the system in Malaysia for the payment of motor vehicle accident compensation to third parties is based on the law of tort relating to negligence. This requires that those who are at fault in motor vehicle accidents should pay compensation for the damages they caused.

The "fault-based" approach under English common law requires that the negligence of the party causing the damage be established by the accident victim seeking redress. Compensation for damages cannot be claimed, unless it can be established that the traffic accident was due to the fault of someone else. Compensation is also reduced to the extent that the victim contributed to the accident.

The advantages and deficiencies of the tort system are well known:

i) The concept of "fault" in negligence carries the overtone of moral blameworthiness, so that the courts feel the need to extract large sums, in an environment of unlimited third party liability from the "delinquent" by way of punishment for "misconduct" when injury is caused. In reality, a large number of motor vehicle accidents are not due to blameworthy conduct, but errors due to human imperfections.

ii) In an environment where civil litigation takes too long, motor accident litigation usually takes years to settle, resulting in hardship to victims and pressure to settle for less, and increased costs for insurers. Costs are also increased because insurers are systematically tempted to decline their responsibility and to subsequently defend the insured because it may be in their interest to do so.

iii) In addition, the attraction of large compensation encourages litigation by accident victims, especially under the "contingency fee" system under which lawyers work on "no-cure-no-fee" basis for a proportion of the compensation and could also lead to touting. The use of touts presently to secure cases for some lawyers is viewed as a serious problem in the country. 
iv) There is a lack of uniformity in awards made by different courts for similar events or injuries as the Civil Law Act, 1956 as amended by the Civil Law (Amendment) Act, 1984 , provides for a large degree of discretion to the judiciary in determining the quantum awards. The end result is sometimes large compensation for a fortunate few, often without sufficient regard for other awards for similar injuries or circumstances, and little or no compensation for the vast majority.

v) In some countries, the solution taken to these problems has been to revise the basis of compensation to one which is termed as a "no fault" system. This system involves prearranged limits for specific types of injury and fundamentally pays little attention to apportionment of the fault. It dispenses with the use of the courts as the arbiter for this and the awards arising therefrom. This is a complete and radical departure from their previous system and has in instances resulted in greater problems for their insurance industry to bear. The alternative may be a more balanced approach combining some control on the awards and their limits within the existing legal systems.

\section{Conclusion}

As Malaysia becomes a developed nation, the insurance industry will need to respond to the changing and multiplicity of needs of the country for more sophisticated insurance services. In addition to the insurance of the more mundane, insurers will in the future extend their services in manufacturing and construction to more high technology areas such as telecommunication, information technology and other knowledge-based industries.

The impact of GATT will certainly become apparent as we move into a liberalized environment. There is no doubt that Malaysia will gradually open its door to participation by foreign insurers. Conversely, domestic insurers will also look outwards and expand overseas.

At present there is definite progress in raising the insurers' professional and financial strengths to achieve a strong and dynamic insurance industry. The industry's assets account for only about $3 \%$ of the total assets of the nation's financial system. In addition, the insurance density and penetration is relatively low compared to developed countries. There are, therefore, vast opportunities for further growth of the industry.

In this regard, the national policy of achieving developed nation status by the year 2020 remains a committed objective and the insurance industry will definitely contribute and benefit significantly from this vision. 